\title{
Ethnoscapes domésticos y rite de passage: significación y cronicidad del diagnóstico en esquizofrenia ${ }^{1}$
}

\author{
Elisa Alegre-Agís ${ }^{2}$
}

Recibido: 8 de enero de 2016 / Aceptado: 18 de abril de 2016

Resumen. A partir de los resultados de un estudio etnográfico realizado con personas diagnosticadas de esquizofrenia y sus familiares en Barcelona y Tarragona durante un año, se problematizan las transformaciones de los roles y relaciones dentro del espacio doméstico a partir del acontecimiento del primer brote y la asignación del diagnóstico como ritual de paso. Para ello, se recurre a una lectura cultural de la familia, entendiendo el grupo como un ethnoscape específico. Se analiza la concepción de la cronicidad, y sus consecuencias en la conformación del rol de enfermo en el marco de las relaciones de parentesco, y se discuten las paradojas en términos de autonomía para los afectados, debido a la proyección de la connotación cultural de cronicidad.

Palabras clave: esquizofrenia; rol; familia; cronicidad; ritual de paso.

\section{[en] Household ethnoscapes and rite of passage: meaning and chronicity of the diagnosis in schizophrenia}

\begin{abstract}
Based on the results of an ethnographic study with people diagnosed with schizophrenia and their relatives in Barcelona and Tarragona along one year, I problematize the transformation of roles and relationships inside the household from the first burst and the assignation of a diagnosis as rite of passage. I appeal to a cultural interpretation of family, understanding the family group as a specific ethnoscape. I analyze the chronicity meaning, and its consequences in the conformation of the "role of sick person" in the context of parental relationships. I also discuss the paradoxes in terms of autonomy for the affected persons because of the projection of cultural connotation of chronicity.
\end{abstract}

Keywords: schizophrenia; role; family, chronicity; rite of passage.

Sumario. 1. Introducción: conversar sin léxico. 2. ¿Un ethnoscape doméstico? 3. Significación de brote y diagnóstico: ritual de paso. 4. Juego de roles en loops sintomatológicos. 5. "Profecías autocumplidas". 6. Desfase entre la experiencia profana y el conocimiento experto. 7. Conclusiones. 8. Referencias bibliográficas.

Cómo citar: Alegre-Agís. E. (2016). Ethnoscapes domésticos y rite de passage: significación y cronicidad del diagnóstico en esquizofrenia, en Revista de Antropología Social 26(1), 195-217.

1 Los datos y resultados de este artículo forman parte una investigación llevada a cabo entre julio de 2013 y noviembre de 2014, financiada en el marco de la Beca de Investigación del Institut Borja de Bioètica de la Universitat Ramon Llull, convocatoria 2013.

2 Medical Anthropology Research Center

Universitat Rovira i Virgili

elisa.alegre@estudiants.urv.cat 


\section{Introducción: conversar sin léxico ${ }^{3}$}

El concepto de trastorno mental severo (TMS) ${ }^{4}$ es un eufemismo que se utiliza para sustituir las connotaciones de psicosis y cronicidad (Comelles y Martínez, 1994). Es consecuencia de los esfuerzos de unificación diagnóstica derivados del DSM $^{5}$ y el CIE-10 ${ }^{6}$ (APA $\left.^{7}, 1995 ; \mathrm{OMS}^{8}, 1992\right)$, que no contemplan el contexto individual, social y asistencial del proceso de enfermar - y menos aún las especificidades de los trastornos mentales desde el punto de vista de las relaciones sociales y personales (Comelles, 1999; Perdiguero \& Comelles, 2000). Para la Antropología, enfermedad, salud, aflicción y muerte son fenómenos dependientes de la cultura y la vida social (Martínez Hernáez, 2008). Aunque una enfermedad resulte de una causa genética o biológica, no implica que su curso o evolución dependan exclusivamente de estos factores. En las enfermedades mentales no podemos reducir los fenómenos mentales a eventos cerebrales, ya que supone no tener en cuenta que el comportamiento es el resultado de interacciones entre el cerebro y el entorno. Dar por hecho que si el cerebro es «anormal» sólo los medicamentos que actúen directamente sobre él podrían modificar un comportamiento anormal es simplista y falso (Saraceno, 2008: 18-19), ya que, como apunta Eisenberg, 'problems in living' and 'diseases of the brain'are overlapping categories (Allen, 2010: 13).

Durante los dos últimos siglos, la tendencia de la psiquiatría ha sido considerar una parte sustancial de los trastornos psiquiátricos como crónicos, un concepto fruto del artefacto de las condiciones de observación de pacientes internados en los manicomios morales (Lantéri-Laura, 1972). Se proyectó entonces una concepción del loco sobre la sociedad porque a médicos y psiquiatras les convenía asumir la evolución tórpida de una condición humana que se sospechaba permanente, y que derivaba de la concepción cultural de la locura anterior (Comelles, 2013). En esta última, se planteaba menos la condición de enfermedad que la de un estado que afectaba a determinadas personas y resultaba tolerable socialmente en tanto el loco no cometiera "excesos" (Comelles, 2014). La locura y el loco - que no la enfermedad y el enfermo mental- eran imprevisibles, desconcertantes, pero reconocibles culturalmente, y aceptables.

En este artículo exploraremos el concepto de cronicidad ligado a la esquizofrenia a partir de la reflexión derivada de una investigación enmarcada en el campo de la

3 Este título se inspira en los párrafos que Antonin Artaud (1976) dirige "A los Directores a los Asilos de Locos" donde dice: "Esperamos que mañana por la mañana, a la hora de la visita médica, recuerden esto, cuando traten de conversar sin léxico con esos hombres sobre los cuales — reconózcanlo- sólo tienen la superioridad que da la fuerza". He escogido este fragmento para manifestar que aún nos movemos en un terreno semántico pantanoso en cuestiones de TMS por el desconocimiento que tenemos sobre estos, tanto las ciencias de la salud como las ciencias sociales. Cuando se intentan abordar estas problemáticas, acudimos a los libros para generar un panorama claro y organizado, pero parece un diálogo sin léxico al intenta conversar con diferentes disciplinas.

4 De ahora en adelante, las siglas TMS se usan para hacer referencia a trastorno/s mental/es severo/s entendiéndose estos como un conjunto de entidades nosológicas de diferente naturaleza y presentación clínica, que comparten criterios de gravedad y persistencia en el tiempo. Estarían incluidos en él los Trastornos esquizofrénicos, Depresión mayor recurrente, Trastorno bipolar maníaco, Trastorno bipolar depresivo, Trastorno bipolar mixto, Paranoia, Agorafobia con crisis de angustia, Trastorno obsesivo-compulsivo, Trastorno límite de la personalidad, Personalidad esquizotípica (APA, 1995).

Diagnostic and Statistical Manual of Mental Disorders.

Clasificación Internacional de enfermedades, décima edición.

American Psychiatric Association.

Organización Mundial de la Salud. 
bioética, y cuyo objetivo ha sido analizar las relaciones familiares del psicótico en el espacio doméstico. La etnografía se realizó durante un año, entre 2013 y 2014 en un Centro de Salud Mental Ambulatoria y en dos espacios asociativos. El primero de ellos es una asociación en el centro de Barcelona cuya militancia contra el estigma se desarrolla a través de la actividad radiofónica, así como otras actividades artísticas y culturales que promueven el contacto y las relaciones con otros colectivos y con la comunidad. La entrada y participación plena en esta asociación me permitió acceder a las narrativas de los afectados, tanto desde la observación participante y la escucha de sus programas, como a partir de entrevistas individuales que se concertaron fuera del espacio asociativo. La otra asociación, ubicada en Reus (Tarragona), desarrolla todos los años un taller para familiares de personas afectadas de alguna enfermedad o trastorno mental. En este caso participé como investigadora y como familiar, lo que me permitió acceder a los discursos de los familiares - madres en casi el cien por cien de las reuniones- de forma directa y en un ambiente que se presentaba relajado, cómodo y entre iguales. A partir de esta actividad se propuso a las madres la realización de entrevistas individuales abiertas y en profundidad, las cuales se realizaron en varios encuentros ajenos a la actividad. Por último, hice trabajo de campo en un Centro de Salud Mental Ambulatorio para Adultos (CSMA) en un barrio de Barcelona, dispositivo en el que se pudo realizar observación en algunas de las reuniones de equipo así como entrevistas a los profesionales, concretamente a psiquiatras y trabajadoras sociales. En total se contabilizaron veinte entrevistas en profundidad, incluidas personas diagnosticadas, familiares y profesionales. La etnografía se completó con entrevistas, grupos focales y observación participante durante aproximadamente tres meses con una familia en la ciudad de Tarragona.

La etnografía en estos espacios permitió que el estudio pudiera contemplar dimensiones que inciden en el desarrollo de la vida cotidiana, tanto en el domicilio como en espacios laborales, asociativos e instituciones de atención a la salud mental. Las entrevistas realizadas a pacientes y familiares, con un guion de ayuda-memoria, versaron principalmente sobre la vida cotidiana, las relaciones familiares, sociales y laborales, el estigma, la autopercepción, concepción, entendimiento y simbolización subjetiva de los trastornos. Se realizó un recorrido biográfico y una trayectoria desde el primer brote o descompensación, procesos de internamiento, establecimiento del diagnóstico e itinerario terapéutico. Los diferentes puntos de interés se priorizaron en función de si los informantes eran personas diagnosticadas o familiares aunque dependía también del desarrollo de las entrevistas y la comodidad del entrevistado sobre las temáticas abordadas.

Para este artículo he decidido centrarme en una parte del estudio, concretamente en el acontecimiento del primer brote y la asignación del diagnóstico. Esta fase será analizada como un proceso equiparable a lo que entendemos como un ritual de paso (Van Gennep, 1981 [1909]) en el que se adquiere la identidad de enfermo. Respecto a la bibliografía citada en este artículo, se ha recogido aquella pertinente al análisis, haciendo uso de conceptos provenientes de estudios de antropología clásica y sociología sobre instituciones. El objetivo desde un punto de vista epistemológico es utilizar categorías clásicas para un análisis actual, por lo que las referencias serán siempre las originales. Por otro lado, no se han encontrado referencias de estudios actuales que realicen un análisis del espacio doméstico desde esta perspectiva teórica. A partir de estos supuestos, se abordará principalmente el impacto y resonancia en las relaciones intrafamiliares de la introducción del trastorno mental en el espacio doméstico. 


\section{2. ¿Un ethnoscape doméstico?}

Generalmente entendemos el espacio doméstico como aquellas estructuras, instalaciones, áreas de actividades y de trabajo asociadas a un grupo primario, una de cuyas formas es la familia. Sus características comunes son la realización de actividades cotidianas, la co-residencia y algún tipo de relación de parentesco (Hendon, 1996). Aunque el espacio doméstico siempre ha sido considerado una arena de interacción social se abordará también como una arena cultural a partir del concepto de ethnoscape. Según Appadurai, el ethnoscape (paisaje étnico) refiere a que la identidad de un grupo no debe ser pensada como algo limitado, fuera de la historia, culturalmente homogénea, o fuertemente territorializada como planteaba la tradición culturalista en la antropología, sino que se trata de una realidad profundamente interactiva (1996) . En esta misma perspectiva, el autor considera que la localidad es principalmente relacional y contextual, un complejo de calidad fenomenológica, constituida por una serie de vínculos entre el sentido de las inmediateces sociales, las tecnologías de la interactividad y la relatividad de los contextos (Appadurai, 1996).

Este enfoque nos permite profundizar en la comprensión de los rasgos culturales de la vida cotidiana, en la diversidad social entre unidades domésticas y su importancia para la articulación con universos sociales más amplios (Robin, 2003). Siguiendo a Blumer (1969), nos ubicaremos en la perspectiva del interaccionismo simbólico, donde la cultura es un concepto semiótico, y en el que el ethnoscape conformaría una urdimbre con tramas de significación propias de una "micro-sociedad" dinámica.

La familia, como caso específico dentro de los grupos primarios, se ha transformado profundamente en las últimas décadas. Sin embargo, podemos considerarlo como un caso elemental de ethnoscape. Siguiendo la línea interactiva que propone Appadurai para el análisis de los grupos, para el caso del ethnoscape doméstico, tomaremos la perspectiva de análisis de Henry Léfèbvre, en la que el espacio es comprendido como político, percibido y significado, teniendo en cuenta la percepción a escala individuo, de su grupo, la familia y la adyacencia que incluye el umvelt (entorno). De esta manera, el espacio es vivido en estrecha correlación con la práctica social: no resulta jamás ni neutro ni puro, sino que nos lleva a preguntarnos cuál es la relación entre el espacio mental (percibido, concebido, representado) y el espacio social (construido, producido, proyectado) (Léfèbvre, 1972: 23-27). Desde la interpretación que Léfèbvre hiciera del espacio, entendemos que este no es ni un punto de partida ni un punto de llegada, sino un intermediario, un procedimiento y un instrumento, una mediación que vehicula las normas y los valores de la sociedad burguesa (1972: 30-33). En este caso, lo comprenderemos como vehículo del sistema de valores sociales del ethnoscape doméstico para preguntarnos cuál es la significación de un brote y un diagnóstico de esquizofrenia. Esta lectura de espacio doméstico y de las relaciones que suceden en él nos permite dar cuenta y poner de relieve las diferencias en cómo es percibido, definido, simbolizado y aceptado o procesado el diagnóstico, ya sea desde la perspectiva del enfermo o de la familia. Esto nos permite ahondar en las diferencias no sólo entre los miembros del ethnoscape en tanto grupo que interactúa, sino también en la relación entre este y el entorno social más amplio, incluyendo la concepción cultural del loco, que abarca el problema del estigma, la cronificación y la negación de su figura. Del mismo modo, nos permite

Traducción de la autora. 
conocer los vínculos con el sistema experto y su impacto en virtud de la idea de cronificación y biologización del trastorno. En todo caso, se trata de ubicar a los miembros en una realidad interactiva, atravesada por la sociedad y las diferentes variables que influyen en su estructura de roles. De este modo, el análisis de las dinámicas de cuidado pone de relieve los conflictos interpersonales dentro y fuera del ethnoscape, así como la tirantez y rigidez que caracteriza algunas relaciones entre el adentro y el afuera.

\section{Significación de brote y diagnóstico: ritual de paso}

Lo que conocemos como brote es entendido desde la psiquiatría como el "episodio de descompensación de las esquizofrenias, considerados brotes psicóticos endógenos que, a diferencia de las fases del trastorno bipolar, dejan tras de sí alteraciones de la personalidad"10. Desde la perspectiva médica, un brote es aquel episodio caracterizado por la aparición de síntomas psicóticos o de psicosis. Para los familiares es uno de los momentos de mayor dificultad comunicacional, sobre todo cuando los padres hablan del primer brote de sus hijos ligado a un diagnóstico y a un nuevo estatus. Son momentos de incertidumbre, de no reconocer a la persona, desposeyéndola de su identidad anterior. Si entendemos que "la identidad es un concepto complejo y multidimensional que incluye aspectos sociales y culturales" (Restrepo et al., 2007: 210), entendemos también, en el campo del estigma, que el proceso de enfermar y la adjudicación de un trastorno psiquiátrico supone un cambio en la identidad de la persona, quien pasa de una historia previa a ser para los otros "el enfermo", "el esquizofrénico" o "el loco" (Restrepo et al., 2007). Algunos pacientes manifiestan que no se puede hablar con ellos, ya que "cuando estás con el brote, no se puede dialogar con nosotros, no hay manera, es imposible. Tienes que esperar a que se pase para razonar"11.

"El primer impacto de la experiencia de una hospitalización o de un episodio serio que lleva al diagnóstico de una enfermedad mental es el temor a una ruptura en la identidad propia, y a no poder seguir siendo 'la misma persona' y continuar con sus proyectos personales y roles sociales" (Restrepo et al., 2007: 213). Para las madres ${ }^{12}$, tras los episodios que indican que algo anda mal - a menudo un largo proceso hasta alcanzar un diagnóstico definitivo--, sus hijos ya no son la misma persona. Mientras algunas más jóvenes guardan la esperanza de que vuelvan a serlo ${ }^{13}$, otras hacen un

10 Gómez- Feria Ildefonso. Glosario de Psiquiatría [en línea] Copyright 2005-2015 [fecha de consulta: 06 de diciembre 2015]. Disponible en <http:/www.psychiatry.es/b/bk-bt-seccionesglosario-23/4498-brote.html> Número Internacional Normalizado (ISBN) 978-84-611-7548-2.

11 Extracto del diario de campo. Mujer diagnosticada de unos 40 años de edad. Charla informal en un bar, Barcelona.

12 En el taller de familiars de malalts mentals la mayoría de participantes eran madres, exceptuando dos sesiones a las que asistió un padre en cada una. Sobre la figura de cuidadora ver María Antonia Martorell (2009) en donde analiza el vínculo relacional entre cuidador y cuidado, siendo en la mayoría de los casos mujeres quienes asumen un rol que deviene de la construcción social y cultural de la mujer en nuestro contexto occidental cristiano.

13 Por madres jóvenes me refiero a las que tienen menos de cincuenta años y han tenido menos relación con la enfermedad. Las que superan esta edad, suelen estar en proceso de "duelo" o han adoptado una postura resignada en relación a la vida que su hijo/a tendrá con el diagnóstico, dando por imposibilitadas ciertas partes de la vida relacional, sobre todo la vinculada a las relaciones sexo-amorosas con personas que no tengan un diagnóstico, entendiendo en la mayoría de los casos que sólo podrán acceder a tener una relación de pareja 
duelo por la pérdida de la que consideran otra "persona". Les aqueja la pérdida de expectativas y la vida que habían planeado y deseado para sus hijos. Tener planes para el futuro y perderlos ${ }^{14}$ es habitual, pues no comprenden la realidad derivada de la "enfermedad" y su sintomatología, lo que las lleva a intentar "cambiarla"15.

Hacer del loco un enfermo produce una paradoja: mientras algunos padres se sienten aliviados por el diagnóstico que explica el comportamiento de sus hijos, otros, dependiendo de su concepción etiológica de la enfermedad, creen haber pasado genéticamente la enfermedad a sus hijos, lo que les genera sentimientos de culpa. Los pacientes, por su parte, tienen posturas diversas: en algunos actúa como significante que explica acontecimientos vividos; en otros se produce una negación, ya que las explicaciones que daban al fenómeno, desde su certeza, resultan incongruentes con el diagnóstico. Otros lo aceptan obteniendo conciencia de enfermedad, una cuestión que algunos consideran imprescindible para un mejor estar. Otros se verán como enfermos mentales crónicos, otros consideran que tienen una enfermedad, pero que no está presente todo el tiempo, o incluso que es algo que está ahí pero que les es ajeno. Algunos, por último, prefieren su propia explicación y significación de los "síntomas", lo cual puede resultar positivo al no identificarse desde la categoría de enfermo total ${ }^{16}$ (Correa-Urquiza, 2009), sino desde categorías significadas por su experiencia vital.

El paso de una concepción cultural de la locura a la de enfermedad mental crónica estaría limitando las posibilidades terapéuticas en tanto no se la considera curable. Sin embargo, se estima que pueden recuperarse "partes" de la persona anterior y restablecer la vida social o relacional que tenía antes del diagnóstico. ${ }^{17}$

La evolución de la doctrina psiquiátrica y la biologización de la causalidad desde el degeneracionismo del XIX y sus efectos (Huertas Garcia-Alejo, 2012), así como la hegemonía de la idea de cronicidad en psiquiatría proyectan sobre la cultura occidental la idea de un "cuerpo esquizofrénico" equiparable al enfermo total. Con la cronicidad se desvanece "la persona anterior al diagnóstico" y la idea según la cual alguien se ha "trastornado" refleja esa situación post-diagnóstica como una pérdida en términos de "muerte civil" (Goffman, 1961). ${ }^{18}$

Mi hijo ya no es quien era... yo estoy haciendo un duelo ahora, tengo que aceptar, aún estoy asimilando que mi hijo, el que yo tenía planes para él, el que creía que iba a ser una cosa, que tendría una vida normal, un trabajo, una pareja...que me daría nietos...

con alguien con su misma problemática o similar. Una excepción es el caso de Rocío, de 65 años, con un hijo diagnosticado desde 1998, y que piensa que su hijo podrá tener una relación con una mujer "normal" aunque aún él no haya encontrado a la "persona adecuada", tal y como suele decirle a su hijo "para animarlo".

14 Las palabras en cursiva son aquellas que las madres han utilizado para describir el proceso posterior al primer brote y la asignación de un diagnóstico.

15 La información de este párrafo y el siguiente está extraída de las grabaciones personales posteriores al taller de familiares e incluidas en las notas del diario de campo. Las explicaciones de la significación del diagnóstico están deducidas de las entrevistas realizadas, de la observación participante y de las conversaciones informales.

16 El trastorno y sus significaciones para los cuerdos impregnan el tejido de vida del sujeto que deviene así en una suerte de enfermo absoluto, y que lejos de ser pasivo, significa su espacio; no sólo está, sino que es enfermo, y lo es en todas las instancias de su yo cotidiano (Correa-Urquiza, 2009).

17 Si bien existe un cambio semántico al pasar de enfermedad a trastorno, en el imaginario cultural e incluso entre los profesionales de la salud mental se sigue usando el término enfermedad.

18 En la concepción pre-psiquiátrica de la locura, los límites porosos entre el ignoscent, el foll o el aurat no planteaba ese problema puesto que formaba parte de una cotidianidad inevitable, fruto de los designios arbitrarios de Dios. 
ese hijo ya no está. No va a volver. Yo lo quiero igual, sigue siendo mi hijo, pero estoy en un duelo, tengo que yo asimilar que todo eso no va a pasar, y tratar de que sea feliz con esta enfermedad. No será lo que yo hubiera querido para él como madre, que quieres la felicidad para él. (Carmen, madre, noviembre 2013. Reus) ${ }^{19}$.

La "muerte" de un sujeto y el nacimiento de otro nos interesan por sus efectos en la convivencia tras el diagnóstico. Para ello acudiremos al concepto de rito de paso que formulara Van Gennep (1981[1909]) y que acompaña todo cambio de lugar, estado, posición social y edad, y que se caracteriza por tener tres fases: separación, margen o limen, y agregación ${ }^{20}$. La sintomatología del brote psicótico podría asociarse al periodo de separación del rito de paso, que la familia describe como "ver rara a la persona" y que marca un punto de inflexión. Desde la manifestación de estos síntomas, hasta la asignación de un diagnóstico definitivo, el sujeto entraría en fase liminal, en tanto no es reconocible por su entorno social para directo y se encuentra en un estadio confuso en el que se estaría produciendo una transformación de su identidad, un cambio en pleno tránsito y una ausencia de "identificación" del sujeto desde los que los rodean. Observando los atributos de la persona liminal, se ve una analogía con la etapa en la que el brote aparece por primera vez. Los síntomas y su impacto cultural en un plano comportamental ubican al sujeto en un estado de incertidumbre. Algunos familiares creen que están pasando por una depresión, consumiendo drogas, una etapa de rebeldía, o incluso que podrían estar poseídos por el demonio ${ }^{21}$.

Los atributos de la liminalidad escapan al sistema de clasificaciones que establecen las situaciones y posiciones en el espacio cultural, y no se les puede situar en las posiciones asignadas y dispuestas por la ley y la costumbre, las convenciones y el ceremonial (Turner, 1969). Por eso, la liminalidad se compara con la muerte — podríamos decir muerte civil en términos de Goffman —; con la invisibilidad —invisibilidad social del loco por el estigma_-; la oscuridad — resultan peligrosas para el común de la sociedad a partir de la concepción de imprevisibilidad y los juicios morales de sus conductas, ubicándolos a veces en un plano mundano-; y la soledad — vinculada a la auto-reclusión por la incomprensión_— ${ }^{22}$. Durante la fase liminal, las familias no reconocen a la persona, desconfían y temen de lo que pueda llegar a

19 Carmen, madre de un chico de 23 años diagnosticado de esquizofrenia paranoide. Carmen es enfermera y ejerce como tal en la misma ciudad que reside. Es viuda desde el nacimiento de su hijo y no tiene más hijos. Su hijo no trabaja, ni tiene pensión por discapacidad con lo que ella se hace cargo de todos los gastos y del cuidado éste. Ella acude a terapias alternativas para gestionar el estrés y practica natación a diario. Es muy activa en cuanto a la búsqueda de información sobre la enfermedad de su hijo y manifiesta que trabajar en la esfera médica no ha sido relevante para aceptar la enfermedad de su hijo. Participa en varias actividades de asociacionismo y esto le ha ayudado en los procesos de aceptación y gestión de los problemas.

Su hijo no realiza actividades más que unas pocas salidas, lo cual lo dota de una red social poco amplia. Se realizaron dos entrevistas en profundidad y encuentros en el espacio de asociación.

20 La fase de separación comprende la conducta simbólica por la que se expresa el desprendimiento del individuo de la estructura; la de margen (limen, umbral) es el periodo de ambigüedad que atraviesa un entorno cultural y que vacía al sujeto de los atributos pasados o venideros; y la de agregación o reincorporación consuma el paso a un estado relativamente estable a derechos y obligaciones de un tipo claramente definido y estructural (Turner, 1969).

21 Estas definiciones de los familiares sobre la concepción de lo que sucede cuando el diagnosticado está atravesando el brote han sido extraídas de las entrevistas hechas a las madres y de las observaciones y escuchas en el taller de madres de Reus.

22 El loco en el periodo pre psiquiátrico se sitúa en una posición claramente liminal (Ver Zijderveld; 1982) lo que le confiere atribuciones particulares como personaje que puede actuar en determinados procesos de mediación. 
hacer porque no pueden razonar con ella; surge un malestar porque lo anteriormente conocido - la identidad previa a la alteración del comportamiento - no sirve para solventar estos momentos:

Es que no era mi niña $[\ldots]$ yo pensaba, mi hija ha fumado, no puede ser otra cosa $[\ldots]$ y me decía: ¡me van a matar, o me vas a matar tu o los toros... que yo no me voy contigo! [...] pero yo quería traerla a casa, que durmiera. Yo aquí digo mi hija está mal... quiero que duerma $[\ldots]$ en un momento creía que estaba poseída por el demonio, lo llegué a pensar, ya se me pasó lo de las drogas [risas] y ya pienso esto es una posesión...porque empezaba que quería una cruz: ¿mamá y mi cruz? [...] y estábamos las dos en el cuarto, y yo no podía salir porque creía que si salía del cuarto vendría a por un cuchillo para matarla, entonces no me quería dejar salir, y me tenía arrinconada, no podía coger el teléfono para llamar a la familia, ni a su padre [risas de Irene] ni a nadie, pero tenía una fuerza bruta [...] (María, madre, febrero de 2014, Tarragona) ${ }^{23}$.

Es que no lo reconocías, no había manera de convencerlo... yo pensé, me lo traigo para Reus y ya, eso era lo que nosotros queríamos, pero no podíamos convencerlo [...] al final fuimos a hablar con un médico, y su padre fue a hablar con un juez para hacer el ingreso involuntario... ¿y tú sabes cómo son los ingresos involuntarios verdad? Aquello es un sin vivir...ya no sabíamos más qué hacer, y bueno, aquello fue... policía, bomberos, los de la ambulancia... y cuando se lo llevaron nos echó una mirada, nos mató con esa mirada... le habíamos traicionado [...] (Rocío, madre, abril de 2014, Reus) ${ }^{24}$.

La identidad de las personas afectadas por el brote resulta ambigua porque escapa al sistema de clasificaciones. Observemos que María cree que su hija ha consumido drogas y posteriormente cree que está poseída. La ausencia de reconocimiento lleva a que la madre de Irene intente explicar y clasificar la identidad de su hija en algún lugar "reconocible". Turner nos dice que los liminales se representan como seres desposeídos, sin estatus, distintivos, rol, ni posición en un sistema de parentesco cuando describe los rituales de paso de los ndembu ${ }^{25}$. Durante el brote encontraríamos algunos de esos atributos según la percepción que de él tenga la familia. Las personas descompensadas o en brote por una esquizofrenia son percibidas como desposeídas

23 María es madre de una chica de 30 años diagnosticada de trastorno esquizofreniforme que vive en otro domicilio con su pareja. María vive con su marido, una hija menor y su padre. Su madre (también diagnosticada de esquizofrenia) está en una residencia, era activa laboralmente, pero hace años decidió dejar el trabajo para "atender" a su hija y a sus padres. Se hace cargo de las tareas domésticas, no realiza actividades constantes fuera del hogar, pero goza de una buena vida social y de un red soporte no muy amplia aunque sí muy fuerte. No comenta la problemática más que con personas de mucha confianza como familia cercana y alguna amistad. Se realizó una entrevista en profundidad, dos grupos focales con la familia y algunos encuentros informales en el hogar a modo de observación.

24 Rocío tiene 65 años y es madre de un hijo de 30 años diagnosticado de esquizofrenia paranoide el cual vive en otra comunidad autónoma. Tiene una hija menor que vive cerca y dos nietos. Rocío es jubilada y viuda desde hace menos de seis meses (a fecha de la $1^{\circ}$ entrevista). Su hijo es muy independiente, aunque tienen una relación telefónica diaria. Su hija menor es un gran soporte para ella y sus nietos la ayudan a seguir manteniéndose activa. Tiene una red social amplia y realiza varias actividades, entre ellas las del asociacionismo. Se realizaron dos entrevistas en profundidad y encuentros en el espacio de asociación.

25 Víctor Turner realizó trabajo de campo entre los ndembu de Zambia, de los que estudio sus procesos rituales entre otras cuestiones relacionadas con la estructura de su sociedad, considerados sus trabajos, junto con los de Clifford Geertz, los más importantes e influyentes de la Antropología Simbólica. Ver Turner (1967) y (1969), en bibliografía. 
de sí mismas; sus familiares expresan que no se comunican con la misma persona, no reconocen al sujeto porque cambian su modo de relacionarse e interactuar. Estas personas pierden su estatus porque ya no pueden cumplir con los roles asignados por desconfianza o miedo por parte de la familia, lo que lleva a una desestabilización y fisura de la identidad conocida.

No cambia la posición en el sistema de parentesco, pero sí se alteran los roles predeterminados en la estructura familiar. Dos jóvenes que tienen hermanos diagnosticados de esquizofrenia - Mariana y Tony ${ }^{26}$ - reconocieron algo parecido, vinculado a sus sentimientos, a partir de la aparición de la enfermedad. Si bien seguían queriendo a sus hermanos, se modificó la relación parental. Ambos son hermanos menores de diagnosticados y ambos ven cómo la enfermedad los ha subordinado en su rol de hijos, ya que muchas atenciones que consideraban que les pertenecían han ido a parar a sus hermanos mayores diagnosticados. Para Tony es muy difícil ver a su hermano con los mismos ojos. Se siente responsable de él y ha tenido que aprender a desprenderse y cargar con la culpa de desligarse de la "tutela moral". Mariana ya no puede hablar con su hermana Irene como lo hacía antes. No quiere rallarla con sus problemas y ya no le cuenta sus cosas. Pretende aliviar parte de la carga de su madre y ve que su hermana y su madre tienen una relación mucho más estrecha, ella ha "ido más a su bola" para no cargarla con más problemas. María, madre de ambas, es consciente de que presta más atención a Irene e intenta que Mariana haga lo que su hermana no puede hacer. Los vínculos se mantienen y los roles son inmóviles en su representación estructural, pero se alteran las formas en que estos se desarrollan, generando sentimientos de angustia, sufrimiento y hasta culpa por esta variación del estándar de relaciones que se entienden inherentes al parentesco.

Según Turner, la conducta en la etapa liminal suele ser pasiva o sumisa, los iniciados deben obedecer implícitamente a sus instructores y aceptar cualquier castigo que pueda infringírseles (Turner, 1969). Los afectados en brote no resultan ni sumisos ni pasivos según sus familiares, porque la alteración sucede en un marco de acontecimientos sobrevenidos e inesperados. Los rituales de paso de los ndembu, sin embargo, son "esperados" o previstos. El brote y la enfermedad mental, en nuestra sociedad no lo son y explica la diferencia de sumisión o actitud pasiva entre uno y el otro. En el taller de madres oí repetidas veces que los hijos no hacen caso y no hay forma de hacerlos "entrar en razón, están en otro lado, en otro mundo". Se viven simultáneamente dos realidades culturales donde familias y pacientes expresan la imposibilidad de comunicarse desde el mundo de vida que cada uno experimenta. Se sienten amenazados por un miedo mutuo, defendiéndose desde sus propias certezas, con lo que ninguno resulta ni sumiso ni pasivo, sino que intentan demostrar la veracidad de su mundo. Esto genera choques comunicacionales constantes y desconfianzas que derivan - algunas veces - en actitudes opresivas por una parte, y actitudes de defensa personal por la otra.

Con la idea de "hacer caso a los instructores", podemos ubicar este fenómeno en la figura de los médicos que pretenden un "buen paciente" en tanto creen que el éxito del tratamiento dependerá, en última instancia, de cuánto caso haga este a sus direc-

26 Ambos jóvenes hermanos de diagnosticados. Mariana, en el momento de la investigación, tenía 25 años y era estudiante de máster, muy activa y realizaba viajes de intercambio de forma constante. Si bien no es relevante para el análisis de este artículo, Mariana se suicidó hace algo más de un año. Tony, también de 25 años es francés pero vive en España desde hace algo más cuatro de años, con lo que tiene lejos a su familia y su hermano. Tony es músico y vive con su pareja. 
trices. Desde la psicoterapia se intentan corregir conductas del diagnosticado, dado que se considera la "recuperación" como un proceso personal de cambio de actitudes, valores y objetivos propios: una especie de reminiscencia del "tratamiento moral" que individualiza la enfermedad. Ideas de doble filo que descargan sobre el paciente la responsabilidad del mal que lo aqueja y que le impide comprender la gama de tratamientos posibles, apartándolo implícitamente de todo tratamiento y dando por sentado que la cura depende de la capacidad de amor propio del paciente (Sontag, 1980). Su espacio, a partir de la "sentencia" que impone el diagnóstico psiquiátrico como una suerte de "etiqueta irrefutable" es el de estigmatizado, de enfermo, un noespacio, una no-opinión, una no-persona, si pensamos al individuo como resultado del vínculo social. En la mayoría de los casos se trasladan socialmente sin un arraigo identitario, sin un rol, sin una identidad que vaya más allá de la patología. Es precisamente en esta realidad que el estigma se transforma en una vivencia cotidiana que es a la vez causa y consecuencia de una gran parte del mal-estar (Correa-Urquiza, 2005), en tanto el estigma impregna el tejido vital del sujeto estigmatizado. Bajo este marco, el "estigma sentido", es decir, la percepción de quienes han sufrido el estigma (Lee, 2002), tiene un importante impacto sobre el acceso a los servicios de salud y en el desempeño social y laboral de los pacientes. Este estigma se construye a través de un problema de conocimiento (ignorancia), un problema de actitud (prejuicio) y una conducta (discriminación) (Restrepo et al., 2007). De esta manera, las características del estadio liminal están, en cierta forma, ligadas a las consecuencias del estigma en nuestro contexto cultural en tanto, el estigma y sus consecuencias negativas "incluyen el ostracismo y el aislamiento, la desmoralización, la desesperanza, la baja autoestima y una menor búsqueda de ayuda. En ocasiones, el efecto del rechazo y el estigma puede ser más nocivo que los síntomas mismos" (Restrepo et al., 2007: 208). El sujeto debería hacer caso tras el diagnóstico: ésta una característica del estado liminal que permanece al acabar esta etapa (Turner, 1969). Por ello es necesario plantear la introducción de otro fragmento intermedio en el que quedaría anclado el sujeto con un TMS crónico y que guarda simultáneamente atributos del estado liminal y del de reincorporación. Una vez pasada la etapa de incerteza devenida de los "síntomas" y haberse asignado un diagnóstico, no puede ubicárseles simplemente en el estado liminal, ya que el diagnóstico otorga un nuevo estatus y recibe "un estado relativamente estable, con derechos y obligaciones de un tipo definido y estructural". Simultáneamente permanecen características de la liminalidad en tanto se sigue percibiendo a un sujeto ambiguo por su imprevisibilidad, lo que lo ubica en un umbral en relación a la estructura. Esto evidencia la necesidad de una etapa entre el estadio liminal y la re-agregación a la cual llamaremos "intersticio" y que deja al sujeto en un espacio dentro y fuera de la estructura social. En este estadio "intersticial" el "loco" pierde el reconocimiento de vínculo social generalizado (el momento de fractura que supone el brote) y a su vez se genera un vínculo social nuevo caracterizado por la identidad enfermo total. Entendemos que en la fase de re-agregación reaparecería la multiplicidad de vínculos estructurales, pero es justo esto lo que no sucede al enfermo, su vínculo con la estructura quedaría en una anquilosis de contradicción (la fase "intersticial") entre la liminalidad (no recupera una identidad personal) y la re-agregación (queda fosilizado en la identidad de enfermo total).

El estado liminal no se limita a la experiencia individual, sino que incluye a las demás personas que construyen el ethnoscape derivado de la relación entre cuerdos y locos, en una confrontación cultural entre ambos cuando el brote aparece. Las ma- 
dres dicen que cuando sus hijos están en "crisis", ellas, sus esposos y otros familiares convivientes también lo están. Afecta a todos en términos emocionales porque "nunca se está solo cuando acontecen" y "normalmente se puede acudir a otros familiares o amigos muy cercanos" para que ayuden a contener la situación ${ }^{27}$.

Cambia la organización en el sistema familiar y toca estar pendiente de alguien que no se sabe en qué momento puede volver a descompensarse. Estos cambios requieren de la participación activa de los familiares y genera un cambio ${ }^{28}$ molecular a partir del diagnóstico. El concepto de "molecular" de Antonio Gramsci que analiza Giovanni Pizza (2005) encuentra en la expresión la posibilidad de referirse a la unidad mínima de la experiencia vital, al particular inmediato, tomado de la vida cotidiana, y que pretende recoger los procesos de transformación, poniéndose en el punto más cercano a la experiencia hasta individualizarlos en el propio cuerpo y en la propia persona (Pizza, 2005: 23-24). Este concepto nos sirve para dar cuenta de los cambios súbitos en la persona, las transformaciones comportamentales repentinas, la "metamorfosis" relativa a la identidad y la versatilidad que sufren las relaciones interpersonales de los sujetos convivientes. Por ejemplo, algunas de las madres manifiestan que han tenido que cambiar la visión del mundo que les rodea, y sobre todo del espacio doméstico que ahora está ocupado y significado por la figura del enfermo:

No te acostumbras nunca a ellos... ahora ya sabes más o menos qué debes hacer y cómo actuar, pero no te acostumbras...siempre lo pasas mal, siempre es una sorpresa, siempre es un sin vivir de cómo acabará, de cómo hacer, de cómo convencerlo para que se ingrese... así es siempre. Nunca estás suficientemente preparado para el próximo, ¡ch! ¡Qué va! (Rocío, madre, abril de 2014, Reus).

Con Irene me pasa que siempre me coge desprevenida. Yo siempre estoy pendiente, ella come aquí en casa y hablamos por teléfono, entonces yo la voy viendo, con sus pensamientos raros y tal y los razonamos... pero, siempre que le dio los brotes, yo estaba con la guardia bajada... o estaba con mi madre que también está enferma [La madre de María está diagnosticada de esquizofrenia residual] con mi suegra en casa, o con mi padre que está aquí, como con muchas cosas isabes?, como que cuando yo digo, va, la Irene está bien, y bajo la guardia, ahí va y le pasa. Siempre me siento mal con eso, como que yo debería estar siempre atenta, y cuando no puedo estar atenta a ella le pasa esto. Como que pasara para avisarme que no puedo bajar la guardia (María, madre, febrero de 2014, Tarragona).

Las modificaciones, que podemos calificar como moleculares, responden a cambios en la identidad del sujeto y los familiares lo asumen de esta manera:

A partir de esto, tu cambias todo...la vida te cambia completamente... yo antes trabajaba, y me lo he tomado siempre muy en serio, trabajaba muchas horas y tal. Pero con lo de Irene, fue lo que me hizo dejar el trabajo y estar por ella; a ver, que ella es una

27 Esta información procede de las entrevistas a las madres y de los relatos del taller de familiares.

28 Estos cambios en las madres como personas diferentes, y los cambios en la cotidianidad que podemos hacer extensible en cierta medida también al resto de familiares convivientes, se deducen de las entrevistas realizadas a las madres, pero sobre todo a partir de los relatos en el taller de familiares. 
niña muy independiente y muy lista y muy inteligente, y esto ayuda mucho, porque ella reflexiona, ella piensa y se da cuenta de las cosas, y te pregunta, pero claro, tú estás ahí pendiente, no le puedes dejar de hacer caso, de verla, de cómo habla, qué te dice; que si fuma más, que si hace más cosas y esta eufórica es que le está por dar, y así. Yo es que la observo mucho, y ella me cuenta (María, madre, febrero de 2014, Tarragona).

Cada vez que una crisis sucede vuelve a modificar las posibilidades de acción de la familia y suele abrirse el abanico de estrategias de atención a través del conocimiento adquirido.

\section{Juego de roles en loops sintomatológicos}

Los "no diagnosticados" tenemos un status que permite multiplicidad de roles y cierta facilidad de diversidad relacional para interactuar con el exterior. El diagnosticado, en cambio, ve invadidas y mermadas sus capacidades de acción por el status de enfermo ${ }^{29}$. Caudill (1958) analizó el juego de roles de los pacientes dentro del hospital psiquiátrico, entre el rol personal, el de enfermo y el de paciente. En el ethnoscape doméstico el rol personal (vinculado a un rol parental específico) queda desplazado por el de enfermo/paciente, como en el ritual de entrada en el manicomio (Goffman, 1961) cuando el sujeto era desposeído de su identidad personal al cambiar su vestimenta personal por la del hospital, al arrebatársele sus objetos personales y ante la imposibilidad de interactuar horizontalmente con el personal sanitario; adquirían un estatus que no da lugar a relacionarse en esa micro-sociedad desde la multiplicidad de vínculos, sino como enfermo, y en última instancia, como paciente.

El espacio doméstico se adapta al sujeto enfermo, se connota patológicamente porque ahora no sólo es de convivencia, sino también de atención y cuidado; este espacio es ahora donde acaecen la mayoría de procesos terapéuticos, como tomar la medicación o ser observados "constantemente" para "detectar" comportamientos indicadores de descompensaciones. En algunos casos también se les arrebata algún objeto si se considera perturbador - la TV o algunos programas determinados, la radio o incluso el ordenador como en el caso de Adrián-, les hacen suspender actividades como escribir poesía, o tener una pareja si esta está también diagnosticada de un TMS, por considerarlo un "potenciador" de síntomas y brotes. Si en algunos casos estos impedimentos pueden resultar positivos para un mejor estar, hemos de tener en cuenta que esa lógica responde también a necesidades e intereses de los familiares. Uno de los psiquiatras entrevistados explica que cuando se medica al paciente, se medica, en cierta manera, a toda la familia. Muchas de las "medidas" que los fami-

29 La identidad de enfermo no eliminaría "sentimentalmente" sus otras identidades sino que imposibilita las otras identidades en tanto roles con obligaciones y derechos como la de hijo, hermano o novio en virtud de lo socialmente esperado. Esto genera una contradicción que es vivida con mucha aflicción por los implicados ya que esta ausencia de identidades son inherentes al parentesco y ofrecen un orden en la estructura de las cosas que se ve truncada y fisurada. Esta espera de que la persona vuelva a ser quien era, o el duelo de haberla perdido, supone, según mis informantes, uno de los elementos que provoca mayor sufrimiento. Se trata de que aún se siente la afectividad por la persona como hijo, hermano o novio, pero esta persona no siempre se encuentra, no siempre aparece, y cuando está, en muchos casos, ha sufrido una transformación que lo desubica del orden de las cosas esperadas culturalmente, deviniendo en el dolor crónico como experiencia compartida del ethnoscape. 
liares toman no tienen la única finalidad de calmar o disminuir las posibilidades de un brote, sino también de reducir formas de estrés en las relaciones familiares. Esto tendría de positivo que si las relaciones familiares son más distendidas y armónicas tendrá una resonancia en la tranquilidad de la persona diagnosticada, ya que el trato de la familia tiene un efecto en su terapéutica y en su cotidianidad. Al decir que la medicación es para toda la familia nos preguntamos hasta qué punto la medicación está provocando sus efectos paliativos, y hasta qué punto el estar medicado modifica el cómo los demás se relacionan con él provocando efectos en la conducta del sujeto en cuestión. No podemos saber las porciones que influyen de un lado o del otro, pero lo que sí podemos, junto con Stanton \& Schwartz (1954) es comprender que el hospital mental no es un espacio donde coexisten dos universos sociales separados, uno corporeizado y percibido por los internados y otro por el personal, sino que hemos de conceptuarlo como una unidad total (matriz interpersonal de sucesos vitales) de orden terapéutico y no ya custodial (Balbuena, 2013). Entonces, tampoco podemos concebir como dos universos separados al diagnosticado y al resto de convivientes en el espacio doméstico. Si en los momentos de brote, el sujeto y sus familiares parecen estar viviendo dos realidades diferentes, sobre todo en términos comunicacionales, no dejan de estar en un mismo "universo" compartido que, justamente, pone de manifiesto que se está interactuando desde realidades paralelas ya que el espacio doméstico es, probablemente, la mayor matriz interpersonal de sucesos vitales.

Poniendo en relación ambos contextos, encontramos que en el pabellón del manicomio los pacientes podían introducir un rol personal, animado y estimulado por los propios pacientes - una vez el sujeto había asumido su rol de enfermo y paciente (Caudill, 1958) - En el espacio doméstico, sin embargo, no existe un "grupo de iguales" con el que interactuar desde el rol personal, supeditando así su comportamiento a una lógica sintomatológica en casi todo el espacio.

Una madre interpretaba que la enfermedad mejoraba con el avance de la edad ya que cuando su hijo empezó con los síntomas a los 14 años era mucho más difícil de llevar: contestaba muy mal, se peleaban y siempre se ponía en contra de ella ${ }^{30}$. Al ver una mejora en la relación y la actitud de su hijo - ahora ronda los 20 años-, la madre ubica el cambio de su conducta en el desarrollo y pronóstico de la enfermedad. Esto bien puede ser cierto, o bien podríamos pensar que debajo del diagnóstico había un adolescente de 14 años con comportamientos y formas de ser propias de esta etapa. Un adolescente peleando y poniéndose en contra de sus padres no es algo exclusivo de los adolescentes con diagnósticos, sino una etapa de paso entre el ser infante y ser adulto; un proceso cultural que determina las variaciones en el comportamiento y en la personalidad (Mead, 1928). Nuestro imaginario cultural conoce la adolescencia y sus características, sin embargo, la madre estaba leyendo a su hijo en clave síntoma, achacando el cambio conductual a la enfermedad y su posible evolución, y no al proceso cultural en que las personas maduran y cambian la forma en que se relacionan y comunican.

Este tipo de lógicas pone de relieve la figura de enfermo total y sus limitaciones para crear otras condiciones comunicacionales e interactivas, ya que, si es leído en clave sintomatológica de forma crónica, el sujeto deviene en conductas crónicas limitadas por las propias condiciones ambientales que el espacio domiciliar genera y

30 Información de extracto del diario de campo a partir de las grabaciones personales tras el taller de familiares de Reus. 
significa. Tanto el espacio como las personas que los ocupan interactúan de forma performativa dentro del ethnoscape, por tanto, cuando la identidad es invadida por la de enfermo total y los comportamientos son leídos en clave síntoma de forma constante, las posibilidades de ser, estar o hacer se limitan, tanto inclusive como podía limitarse dentro del espacio manicomial.

Los diagnosticados suelen estar sujetos a varias reglas en el espacio doméstico: las que podemos considerar habituales en cualquier convivencia familiar, y las añadidas por las características y exigencias del diagnóstico que, dependiendo de los casos y sus familias, son más o menos flexibles. Aquellos que parecen tener más autonomía, en términos de responsabilidad consigo mismo (entendiendo esto como la percepción que la familia tiene del enfermo), parecen gozar de un marco normativo menos estricto, mientras que, aquellos que parecen ser menos responsables están supeditados a más reglas y normas. Esto tiene el efecto de disminuir, paradójicamente, la autonomía e independencia del sujeto puesto que, no acaban de "asumir" o adquirir ciertas responsabilidades consigo mismo porque no se les ofrece un espacio de posibilidades para hacerlo.

Rocío explica con gran orgullo que su hijo, tras acabar la carrera, quiso hacer un máster sin la ayuda de sus padres, aunque ellos insistían en darle apoyo económico. Pasados algunos años el hijo consiguió un trabajo en otra ciudad en la que vive solo hace algo más de cinco años y trabaja en una empresa que le permite trabajar desde casa - el sonido de los papeles cortándose y otros ruidos propios de las oficinas lo alteran y lo ponen nervioso-. En esta ciudad, su hijo sólo tuvo un brote hace ya unos años. A pesar de que el joven está sometido a ciertos niveles de estrés en su trabajo, trabajar desde casa es un factor que le aporta cierta estabilidad y mantiene una relación telefónica diaria con su madre. Antes eran ellos quienes llamaban al chico, pero desde la muerte de su padre es él quien llama a su madre cada día, tomando responsabilidades emocionales con ella. Podemos considerar que su estabilidad se debe, no sólo a la medicación, sino también a la toma de responsabilidades laborales y emocionales como un nicho para generar una interdependencia sana en la que él igualmente es responsable y cuida de otro, saliendo así de la figura de enfermo total y desarrollando una identidad con muchas más posibilidades de actuación.

Podríamos interpretar la serie de brotes — con mayor o menor asiduidad - como una "respuesta directa" al medio ambiente inmediato y a la situación social en la que se encuentra (Freidson, 1970), entendiendo que estas formas de comportamiento "desviado" (el brote y también algunas sintomatologías positivas y negativas latentes de la psicosis) podrían producirse por las presiones o las expectativas que a veces tienen los familiares. En este caso, vemos que el chico está en un espacio propio, donde no tiene la mirada ni el control de la familia de forma constante. Él es quien ha tomado las riendas y tiene poder para la toma de decisiones e incluso se hace cargo de estar presente en la vida emocional de su madre. En sus estados de brote, sin embargo, la reacción del chico era muy diferente, no quería saber nada de sus padres, ni siquiera hacerlos pasar a su casa, ni ir con ellos, ni seguir las indicaciones que estos le daban, ni tomar la medicación o seguir un tratamiento terapéutico. Goffman (1961) explicaba que "sólo contra algo puede surgir el yo", y Basaglia (1972) exponía que allí donde uno se enfrenta es donde puede reconocerse y desarrollar la subjetividad. Es mientras el sujeto aún discute, se enfrenta, toma decisiones y "se 
hace cargo de", que puede interactuar entre vínculos y relaciones que potencien su autonomía.

\section{5. "Profecías autocumplidas"}

En algunos casos encontramos una predisposición ambiental que coincide con lo que Becker (1964) llamó "profecía autocumplida", en la que las personas que rodean al loco esperan de éste una serie de comportamientos, y probablemente él se comportará como tal. Caudill (1958) lo explicó desde el concepto de rol, como una adaptación a la estructura que le rodea y el lugar en que los otros le posicionan, y Cooper (1967) diciendo que los diagnosticados son precipitados a la situación psiquiátrica por terceros, casi siempre por su familia. Personalmente, no creo que la etiología de la enfermedad mental esté siempre en las relaciones familiares, pero sí considero que es posible que ciertas condiciones ambientales favorezcan un brote psicótico no intencionado por falta de herramientas o destrezas en la resolución de conflictos, o bien porque los familiares están en constante alerta.

La madre de un joven escritor de 35 años, diagnosticado de esquizofrenia paranoide, explica que cuando éste se encuentra en periodos de mayor inspiración y escribe durante horas, se avecina un próximo brote. Al parecer no anda errada en su predicción, ya que efectivamente, el brote aparece. Cuando él está en fase de inspiración, la madre y el padre recuerdan al hijo que estar ensimismado en la escritura lo llevará a descompensarse. El hijo concibe esta actividad como una parte fundamental de su vida, preocupándose especialmente por la retórica. El hecho de que los padres estén esperando el brote en estos periodos puede estar afectando significativamente a la aparición del mismo. Podemos pensar que el chico esté descompensándose y por ello está tan inspirado; o bien, que cuando el chico está inspirado, los padres están alerta, lo advierten y lo controlan más de lo habitual, llevando a la descompensación. Responder a esto es como intentar responder si fue antes el huevo o la gallina. Sin embargo, tener en cuenta que hay más de una posibilidad causal para el brote, puede estar dando algunas claves para actuar desde otro lugar en lo cotidiano, y quizá practicar ensayos-errores, en los que si el chico está inspirado los padres no cambien la actitud habitual hacia él, y ver qué es lo que sucede.

Según Radcliffe-Brown (1972) un grupo de personas que interaccionan en un espacio dado, y con cierta estabilidad temporal, establece, al margen de la macro regulación que supone la estructura social de su comunidad, una micro regulación en función de sus características peculiares. Así, esta "micro regulación" supone que en una sociedad compleja, la estructura social no prevé sistemáticamente todas las opciones posibles de comportamiento, aunque sí marque unas directrices principales. $\mathrm{Al}$ analizar un microgrupo debe situársele en su contexto macrosocial, es decir, en la posición que ocupa dentro de la estructura social del macro grupo, y, en una segunda fase, observar las modificaciones secundarias que la propia dinámica del grupo haya establecido dentro de las opciones ofrecidas (Comelles, 1977).

Siguiendo esta interpretación, podemos pensar que en una familia con un diagnosticado sucede una ruptura con la estructura macrosocial, desarrollándose así adaptaciones y desadaptaciones en el microgrupo que obligan a la transformación de los roles, al mismo tiempo que permanecen en términos de parentesco, emocionalidad y afecto. Mientras una madre sigue "sintiendo" a su hijo como tal, los 
comportamientos y la conducta de éste en su calidad de hijo son incongruentes con lo esperado, sucediendo una desadaptación del rol, e incrementando el desarrollo del rol de enfermo por ambas partes.

En función de los datos obtenidos en la investigación de sociedades primitivas u homogéneas, puede establecerse la siguiente hipótesis de clasificación: 1) Variaciones adaptativas, en las que la interacción correlaciona con los presupuestos del modelo estructural del grupo y que puede utilizar adecuadamente los mecanismos de corrección de la desadaptación con los que está dotado cualquier sistema social. Y 2) Variaciones desadaptativas, en las que el proceso interactivo no correlaciona con las normas sociales, porque introduce un elemento imprevisto o incontrolable. En estos casos, el grupo utiliza sistemáticamente mecanismos que fracasan (porque están previstos para corregir variaciones adaptativas, es decir, previsibles), y por ello, los grupos deben recurrir a elementos foráneos. La diferencia entre ambos tipos de variación viene del recurso al entorno social (Lisón Tolosana, 1974).

Una madre ${ }^{31}$ comentaba que un día al llegar a su casa, donde su hijo había estado varias horas solo, se encontró con "ropa tirada, las cosas desordenadas, había cocinado y todo era un desastre". Se sintió realmente furiosa, se puso firme con él, le dijo que ella "no es la criada de nadie, y que estaba harta de ir detrás de él haciéndolo todo." El hijo respondió: “¡Chapó!”. Hasta el momento ella había tenido una actitud pasiva, limitándose a ir detrás de él, limpiando, ordenando y considerando que su actitud formaba parte de los problemas de "dejadez" derivados de la esquizofrenia. No esperaba que ante un "párate" y una reacción de enfado su hijo respondería de esa manera. Si bien su conducta en relación a las tareas del hogar no ha "mejorado" según la madre, ésta reaccionó de una manera que su hijo no esperaba porque se había acostumbrado a una madre servil y cuidadora. Al mismo tiempo, la respuesta del chico también la sorprendió. Ambos estaban actuando en un círculo de roles que tenían definidos y del que no salían. La madre siempre había intentado resolver las cosas a partir de interacciones correlacionadas con los supuestos esperados en un ethnoscape en el que el enfrentamiento no parecía una opción viable. La actitud de romper con ello, desplegar un elemento foráneo y no correlacionado porque rompe con la norma de cuidar, proteger y no enfrentarse, tuvo un resultado "medianamente" positivo para una mejor comunicación en este acontecimiento. Ambos interactuaban dentro de los comportamientos esperados, un tipo de "profecía autocumplida dialéctica" dentro del modelo estructural del grupo. Cuando esto se quiebra, descoloca a los actores; da la sensación de que los roles se suspendieran momentáneamente para dialogar, surgiendo la posibilidad de utilizar elementos "extraños" en tanto fuera de la costumbre, como el enfrentamiento, una figura posible de relación a la que la madre no había recurrido. Tras ese episodio siguió un diálogo tranquilo y con algunas risas de por medio; a ella le hizo gracia la reacción espontánea del chico y se sintió valorada por sus esfuerzos. Ese día, en lugar de mantener una discusión acalorada y conflictiva (como al parecer ella esperaba, por lo que evitaba el enfrentamiento), hablaron y se aceptaron críticas negativas y positivas en un punto de encuentro que permitió compartir dos realidades que estaban mucho más cerca de lo que les permitía ese bucle de comportamientos esperados.

31 Madre participante del taller de familiares, de unos 70 años, antigua trabajadora como auxiliar de enfermería en un instituto mental; su hijo tiene 38 años y conviven en el mismo domicilio junto con el padre. Era una de las madres más participativas en el taller y su marido fue el único que asistió al taller un par de sesiones. Ambos son jubilados y viven en una casa en una zona más alejada de la ciudad. 
Otro caso es el de Irene, quien en su primer brote estaba en una cena con amigas junto con su madre y comenzó a hacer comentarios que ésta consideraba fuera de lugar. Se refería a las amistades presentes como traidoras y posibles homicidas de su progenitora. María, la madre, logró subirla al coche aunque Irene repetía que en la carretera había toros contra los que chocarían y se matarían. Cuando finalmente llegaron a casa, Irene veía a su madre como su potencial asesina y no la dejaba salir de su habitación. Ambas se encontraban en ese espacio solas, y a María le era complicado salir para coger el teléfono y pedir ayuda. Irene tuvo el "extraño comportamiento" de pedir una cruz, una conducta que nunca había tenido. María pensaba que su hija estaba sobrepasada de actividades laborales y académicas, que estaba agotada y que necesitaba era dormir. Sin embargo, pedir la cruz la llevó a pensar que Irene podría estar endemoniada o poseída, de modo que, cuando pudo salir de la habitación llamó a una amiga que estaba en "cuestiones de esoterismo". Nunca habría pensado en esto, pero cree que inconscientemente prefirió pensar a su hija poseída, antes que enferma, ya que también su madre está diagnosticada de esquizofrenia. La "maga" acudió y tras ver a Irene le dijo "tu hija lo que está es como una cabra, fatal, pero no poseída". María hubo de recurrir a otros familiares y llamar a su marido que no estaba en casa, e incluso a su hermano con el que no se hablaba desde hacía ya unos años para que la ayudaran a contener la situación.

María tuvo que hacer frente a variaciones desadaptativas y desplegó mecanismos de interacción correlacionadas y no correlacionadas con los presupuestos del modelo estructural. En primera instancia sacó a su hija de la escena con las amigas —a partir del presupuesto estructural- Pensó que Irene podría haber consumido drogas y que lo mejor era llevársela para que descansara. Posteriormente en la casa, antes de llamar a la familia o a un médico, llamó a su amiga esotérica en un intento de que la ruptura de Irene con la norma fuera por otro motivo antes que un brote psicótico. Los mecanismos propios de una variación adaptativa que María desplegó mientras estaba sola con Irene - casi toda la madrugada- como intentar razonar, explicarle que no quería matarla, insistir en que durmiera, estrategias "habituales" dentro de lo esperado, no funcionaban. Lo que normalmente era fácil con Irene (razonar de forma lógica) porque "es una chica muy inteligente, estudiosa, trabajadora, colaboradora en la casa y muy activa", no resultaba porque eran mecanismos previstos para corregir variaciones adaptativas y tuvo que desarrollar otras estrategias para las desadaptativas. El apoyo del contexto social comporta habitualmente, formas de conducta extremadamente ritualizadas e institucionalizadas, tanto en sociedades "folk", como en grupos urbanos. Sin embargo, hemos visto que a veces romper estos mecanismos puede tener resonancias positivas, ya que por ejemplo, María probó varias cosas antes de las ritualizadas o institucionalizadas. Al otro día (esa noche no pudieron internar a Irene en el Institut Pere Mata), un primo le dio de fumar marihuana en un intento de "calmarla" y relajarla, ya que aún no había desarrollado desconfianza con él. A pesar de que Irene seguía en "crisis", este acto permitió convencerla de acudir a un médico.

\section{Desfase entre la experiencia profana y el conocimiento experto}

A partir del cuestionamiento y la escucha de las relaciones entre pacientes y profesionales observamos una ruptura total y un desajuste entre los modelos explicativos y operativos del sistema experto, y los modelos explicativos y operativos de 
los diagnosticados. Nos encontramos con dos realidades divididas en las que el cruce de un lado a otro es casi imposible si no hay un diálogo horizontal que genere nexos entre las partes a partir del debate y la negociación para acordar o consensuar qué "es" la enfermedad en términos de realidades vividas y experimentadas. Mientras el sistema experto tiene un modelo explicativo que es percibido por los pacientes como una realidad "externa y ajena" al problema, los afectados y los familiares tienen explicaciones que consideran mucho más reales, cuyas bases se encuentran en la experiencia vivida y el padecer en carne propia un TMS. La inclusión, no sólo de sus discursos sino también de su modelo explicativo es necesaria para encontrar puntos de comunión entre las dos realidades que hasta ahora parecen no encontrarse en demasía.

La percepción "ajena" deviene, en parte, por la falta de conocimiento al que los profesionales pueden acceder sobre la alteración de las instancias cotidianas de las personas diagnosticadas. Unos de los profesionales entrevistados, que ejerció como psiquiatra en el antiguo modelo manicomial y que actualmente trabaja en un Centro de Salud Mental Ambulatorio para Adultos (CSMA) lo manifiesta explicando la lógica del actual sistema externalizado para tratar con los pacientes y su consecuente falta de contacto con estos:

En hospitalización hacíamos todo lo que era posible para hablar con el paciente, establecer relaciones, hacíamos grupos, asambleas, toda una serie de lugares de intercambio que es lo que a mí más me interesa de la profesión $[. .$.$] en un hospital tienes$ tiempo y no tienes espacio, todo está cerrado, pero el tiempo te lo puedes administrar, puedes ver un paciente ahora, o luego, sino mañana, porque está allí, es otro concepto. Aquí, en la zona comunitaria del ambulatorio, los pacientes vienen, tú tienes que estar, ellos vienen y se van, es un planteamiento absolutamente inverso (Informante Psiquiatra, Barcelona, enero de 2014) $)^{32}$.

Los profesionales no tienen contacto suficiente con sus pacientes para conocer qué sucede en su vida cotidiana; se ven desbordados por la cantidad de casos que tienen que atender, lo cual incide negativamente en la intervención administrativa y terapéutica. El mismo psiquiatra comentaba:

Esto fue un shock importante, porque de pasar a tener la responsabilidad de 50 camas de agudos, más o menos tenía 5 o 6 psiquiatras en ese momento, cada uno llevaba 8 o 9 y era una cifra manejable, ahora, aquí, llevamos 3.300 pacientes, de los cuales hay como un 800 o 1000 psicóticos (Informante Psiquiatra, Barcelona, enero de 2014).

Las limitaciones en el tiempo, la falta de personal, la fragmentación temática de los dispositivos de atención, el aumento de patologías que se atienden, la proliferación casi industrial de éstas y la tendencia al sobre-diagnóstico imposibilitan que se contemplen las casuísticas y circunstancias biográficas, familiares y ambientales de

32 Psiquiatra del Centro de Salud Mental Ambulatorio donde se realizó observación. Ejerce desde hace unos cuarenta años la profesión, es director del centro y tiene formación en psicoanálisis. El y su esposa con la que comparte profesión son psiquiatras de referencia para una asociación de afectados por problemas de salud mental debido a su apertura y flexibilidad en el marco terapéutico, explicado por las personas de la asociación. 
forma transversal. Para poner de relieve la mirada "ajena" que los pacientes interpretan de los profesionales nos sirve el relato de Antonella:

Me decían tú tienes esto y punto. Es un poco difícil que de un día para el otro te estén poniendo una etiqueta. Yo me negaba hasta que un día empecé a llorar en frente del psiquiatra, de los doctores y una enferma. Les dije vale, igual me está pasando algo, pero explícamelo, hazme entender que me está pasando porque yo sola no puedo. Un día le pregunté (al psiquiatra) para ti qué es lo que me está pasando, porque yo puedo ver mi punto de vista, pero quiero también entender porque tú o un sistema psiquiátrico me juzga sin yo tan siquiera enterarme que es lo que está pasando, entonces él me explicó, con un discurso súper científico: eso es porque te falta dopamina en la parte central del cerebro y tienes más dopamina en la parte frontal. También me dijo que es una movida genética, que desde que estamos en la barriga de la madre estamos predispuestos, llevamos genéticamente la enfermedad entre comillas, el punto es, si detona o no a lo largo del crecimiento de la persona, muy bioquímica y muy científica la explicación (Antonella, Barcelona, enero de 2014) ${ }^{33}$.

El lenguaje médico resulta incomprensible para el "profano" y las explicaciones quedan en un lugar intangible, en el plano de lo conceptual y lo abstracto. Para Antonella, sin embargo, los síntomas son palpables y perceptibles, los experimenta en el cuerpo, son algo sensitivo. La experiencia vivida es lo que convierte en "real" la explicación del trastorno y sus consecuencias; el sufrimiento, el estigma y el rechazo pasan a convertirse en su mundo de vida, rompen sus dinámicas anteriores e interfieren en su relación e interacción con el mundo. Las narrativas de las personas diagnosticadas son personales; el sujeto, su vida, sus emociones y su visión del mundo están presente en el discurso. El diálogo sobre lo que les sucede permite, a través del lenguaje, poner nombre, identificar, valorar, comprender y analizar toda una serie de cuestiones que afectan a su mundo de vida. La hiperactivación de las vías dopaminérgicas puede ser una explicación muy útil en el campo experto, pero en la vida "real" del paciente es algo que se aleja de la comprensión, le falta humanidad, no es identificable y resulta invisible. Uno no puede sentarse a hablar con la dopamina o con los fármacos. El grado de comprensión de la enfermedad, desde el sistema experto, se mide por la capacidad del paciente para parafrasear la definición experta de su patología y es necesario revisar dichos parámetros. Una las psiquiatras entrevistadas explicó lo siguiente acerca de la etiología de la psicosis:

Hay una carga genética evidente, una predisposición a nivel biológico, pero se detona por un cierto ambiente, un desencadenante que hace que la enfermedad debute. Lo ves en la teoría pero luego lo vas viendo también en la práctica clínica, todos los pacientes que a lo mejor a nivel familiar tienen varios casos de esquizofrenia o de trastorno bipolar, está ligado a un nivel genético. A veces no, a veces es el primer caso que ocurre, entonces puede haber habido consumo de sustancias, por ejemplo el cannabis está

33 Antonella tiene 26 años, está independizada y vive con su pareja. Ha vivido en el extranjero en más de una ocasión. Sus ingresos han sido involuntarios. Trabaja y ha estudiado varias carreras que no ha acabado. Es artista y realiza una gran cantidad de actividades. No cobra pensión por discapacidad. Se realizó una entrevista en profundidad y tuvimos encuentros informales sin grabadora y coincidimos es espacios asociativos. Se generó una relación muy cercana, entre otras cosas por nuestra coincidencia de edad, gustos y aficiones que nos permitieron largas charlas en el espacio asociativo. 
asociado con la psicosis, o por haber habido un cambio vital importante, un traslado a otro lugar de trabajo, una situación que les haya causado estrés puntual como la muerte de un familiar, cualquier cosa; o los malos estilos de vida, salir cada noche, llevarse la vida padre, puede acabar llevando a esto. Lo que si veo es gente que tiene esta vulnerabilidad neurobiológica, como si tuvieran unos boletos y que si encima ya le añades un estrés o tal, pues acaba desencadenando esto, como a otra persona le puede causar otro tipo de enfermedad, como enfermedades de colon, no sé (Informante psiquiatra, Barcelona, enero de 2014) ${ }^{34}$.

En este discurso vemos la influencia de la neurobiologización de los trastornos. Si bien se contemplan desencadenantes ambientales, sociales y relacionales, la perspectiva etiológica dominante es la causa genética (un problema de sustancias) y añaden desencadenante como el consumo de drogas (otro problema de sustancias). Lo que se contempla desde el punto de vista ambiental y social del sujeto es el desencadenante (a veces minado de un cierto juicio moral acerca de los estilos de vida), pero no el origen o la etiología del problema. No se pretende con esto generar un debate sobre el origen de la esquizofrenia, sino abordar la discordancia de miradas que pone en evidencia una cuestión de "percepciones" y "perspectivas", y por ende, un problema comunicacional. Cuando pregunté a $\operatorname{Marcos}^{35}$ sobre lo que él considerada el origen de su primer brote respondió que fue por su hipersensibilidad, su permeabilidad al dolor y al sufrimiento. El origen de su brote esquizofrénico habría sido la muerte de su sobrina pequeña y su incapacidad corporal, emocional y mental para soportar la perdida. Las palabras, conceptos, definiciones, significados y simbolizaciones de lo que le sucedió no coincidía, para él, con las explicaciones de su psiquiatra que vinculaba el origen, en gran parte, a su consumo de cannabis. No podemos determinar si se trata de ambas cosas, de la primera o la segunda. En todo caso, esto abre un debate que necesita de un espacio aparte de este artículo; lo que sí podemos contemplar es que, efectivamente, hay un desfase entre una explicación y la otra que necesita ponerse en comunión. Hay una dialéctica fallida entre ambos universos explicativos que no logra "conformar" a ninguna de las partes en términos de entendimiento y en la suele ganar la mirada experta en tanto tiene el poder de un conocimiento legitimado socialmente, mientras que la voz del loco está aún invalidada y desprestigiada a los ojos del experto y de la sociedad.

\section{Conclusiones}

El rol de enfermo y la idea de cronicidad son los pilares principales que culturalmente generan formas de relación que los convierte en pacientes, pero no sólo en su sentido de persona — que es reconocida médicamente-, sino como aquel que recibe la acción del agente. El enfoque de riesgo individualizado en la figura del loco (Lup-

34 Psiquiatra del Centro de Salud Mental Ambulatorio donde se realizó observación. Mujer, de 27 años ejerce la profesión desde hace cinco. Realizó su estancia de prácticas en Estados Unidos, no tiene formación aparte de Psiquiatría la cual cursó en España.

35 Marcos tiene 40 años, está diagnosticado de esquizofrenia paranoide, vive solo con su gato, su perro y sus pájaros. Marcos tiene familia con la que tiene una buena relación, su hermano es quien administra su dinero y da mayor soporte para la gestión de su vida cotidiana. Es una persona con una alta participación e implicación en una asociación y realiza actividades artísticas. 
ton, 1993) descarga sobre éste una serie de preceptos morales en relación a su estilo de vida y comportamientos. Gran parte de esta concepción popular se ha creado por la proyección manicomial y por el tratamiento que hacen los medios de comunicación de masas, reproduciendo una figura esquizofrénica peligrosa y convirtiéndola en una minoría estigmatizada. Los TMS, y concretamente la esquizofrenia, resultan una enfermedad que se considera misteriosa, es temida y es vista como contagiosa (moral o literalmente) (Restrepo et al., 2007). Esto nos lleva directamente a la necesidad de problematizar la idea de "sujeto contaminante" (Correa-Urquiza, 2009) que refuerza, perpetúa y reproduce el estigma, y pone de relieve la evidencia social del sufrimiento (Correa-Urquiza et al., 2006) devenido de la etiquetación diagnóstica de los trastornos mentales.

Encontramos ciertas "inercias" del antiguo modelo manicomial (Correa Urquiza et al., 2006) que se reproducen en los espacios de atención ambulatoria y se trasladan al ámbito doméstico por una correlación de pautas que se han dado durante años desde ámbitos profesionales como la psiquiatría, la psicología o la medicina. El sistema experto genera relaciones con el profano que no son en su mayoría horizontales, sino que se establecen desde la verticalidad de quien tiene el saber/poder, y que se pronuncia como enunciado irrefutable y poseedor de la verdad.

Los modelos explicativos de las personas diagnosticadas y sus familiares están basados en la experiencia empírica de padecer o convivir con el trastorno. No es que quiera "enfermar" a las familias, sino que es necesario comprender que la convivencia con un TMS es también tenerlo, en tanto uno no puede desprenderse de éste como si se tratara de un objeto. Tal y como concebimos social y culturalmente los TMS resultan en sí mismos el sujeto que lo padece. La falta de conocimiento sobre estas patologías hace que el "enemigo" y el objeto de tratamiento no sean identificables y por tanto se "antropomorfiza" e individualiza en el sujeto que carga con ello.

La no identificación del objeto hace que tampoco tengamos claro su abanico temporal y umbrales de gravedad en términos "objetivos" desde un punto de vista clínico —ubicándonos en un plano positivista - con lo que, la tendencia ante esta falta de delimitación hace que la cronicidad sea una respuesta "descarte" razonable en la lógica médica. Así es cómo la figura del enfermo total es lógica en un lugar de incertidumbre, no sólo por la "imprevisibilidad" que el loco tiene en nuestro imaginario, sino porque el no poder identificar el objeto lo convierte en imprevisible, y lo que no podemos identificar se convierte en una alerta constante. Es allí donde la cronicidad "cobra sentido" para el mundo profesional, cuando se intenta categorizar y clasificar algo en unos parámetros limitados, buscando una definición para algo que en realidad, aunque lo identificáramos "objetiva y científicamente", seguiría careciendo de sentido para quienes los padecen. Dos modelos de explicación tan distantes requieren en primer lugar de un punto de encuentro que al menos ponga a nivel semántico las cosas en consonancia, intentar buscar un lenguaje común que contemple ambas realidades.

\section{Referencias bibliográficas}

Allen, David M. (2010). How Dysfunctional Families Spur Mental Disorders: A Balanced Approach to Resolve Problems and Reconcile Relationships. California: Praeger Publishers. 
American Psychiatric Association. (1995). DSM-IV. Manual Diagnóstico y Estadístico de los Trastornos Mentales. Barcelona: MASSON S.A.

Appadurai, Arjun. (1996). Modernity at Large: Cultural Dimensions of Globalization. London: University of Minnesota Press.

Artaud, Antonin. (2012 [1976]). Carta a los Poderes. Buenos Aires: Argonauta.

Balbabuena Rivera, Francisco. (2013). "El Hospital Mental (1954): un texto clásico revisado 60años después”. Revista Intersubjetivo 13: 181-188.

Basaglia, Franco. (1972). La Institución Negada: Informe de un Hospital Psiquiátrico. Buenos Aires: Ed. Corregidor.

Becker, Howard S. (1964). Los extraños. Sociología de la desviación. Buenos Aires: Tiempos Contemporáneos.

Blumer, H. (1969). Symbolic interactionism: Perspective and method. Prentice Hall: Nueva Jersey.

Caudill, William. (1958). The Psychiatric Hospital as a Small Society. Cambridge: Harvard University Press.

Comelles, Josep M. (1977). "Interacción Familiar y Esquizofrenia: Aplicación de un modelo antropológico-social al análisis y terapéutica de un caso clínico". Revista del Departamento de Psiquiatría de la Facultad de Medicina de Barcelona. 23-42.

- (1999). "Locuras, Quejas y Malestares. Cultura, Sociedad y Salud Mental en España". Revista Trabajo Social y salud. 56: 69-110.

- (2013). "De la locura como exceso a la locura como enfermedad". En Simón Lorda, D., Gómez Rodríguez, C., Cibera Vázquez, A. y Villasante, O. (Eds.). Razón, Locura y Sociedad. Una mirada a la historia del siglo XXI. Madrid: Asociación Española de Neuropsiquiatría Estudios/51.

Comelles, Josep Ma; Martínez-Hernáez, Àngel (1994). "The dilemmas of chronicity: the transition of care policies from the authoritarian state to the welfare state in Spain". International Journal of Social Psychiatry 40: 283-295. doi: http://dx.doi. org/10.1177/002076409404000406

Cooper, David. (1985). [1967] Psiquiatría y Antipsiquiatría. Barcelona: Paidós.

Correa-Urquiza, Martín. (2005). "Radio Nicosia: Propuestas para una inclusión real que derive en eje de nuevos caminos terapéuticos". En I Congreso La Salud Mental es Cosa de Todos. El reto de la Atención Comunitaria de la Persona con Trastorno Mental Grave desde los Servicios Sociales. Madrid: Ministerio de Trabajo y Asuntos Sociales, Secretaria de Estado de Servicios Sociales, Familias y discapacidad, Instituto de Mayores y Servicios Sociales.

- (2009). Radio Nikosia: La Rebelión de los Saberes Profanos. (Otras Prácticas, Otros Territorios para la Locura. Tesis Doctoral. Departament d'Antropologia, Filosofia i Treball Social. Universitat Rovira i Virgili.

Correa-Urquiza, Martín; Silva, Tomás J.; Belloc, Márcio M.; et al. (2006). "La evidencia social del sufrimiento. Salud mental, políticas globales y narrativas locales". Revista Quaderns 22: 47-69.

Freidson, Elliot. (1978 [1970]). La profesión Médica. Barcelona: Península.

Geertz, Clifford. (1992 [1973]). La Interpretación de las culturas. Barcelona: Editorial Gedisa.

Goffman, Erving. (1961). Asylums: Essays in the Social Situation of Mental Patients and Other Inmates. Garden City: Doubleday.

Hendon, Julia A. (1996). "Archaeological approaches to the organization of domestic labour: Household Practice and Domestic Relations". Annual Reviews of Anthropology 25: 45-61. 
Lantéri-Laura, Georges. (1972). "La chronicité dans la psychiatrie française moderne. Note d' histoire théorique et sociale". Annales E.S.C. 27: 548-568.

Lee, Sing. (2002). "The stigma of schizophrenia: a transcultural problem". Curr Opin Psychiatry 15: 37:41.

Léfèbvre, Henry. (1976 [1972]). Espacio y politica. Barcelona: Ediciones Península.

Lisón Tolosana, Carmelo. (1974) Perfiles Simbólico-Morales de la Cultura Gallega. Madrid: Akal.

Lupton, Deborah. (1993). "Risk as Moral Danger: The Social and Political Functions of Risk Discourse in Public Health". International Journal of Health Services 23: 425-35. doi: http://dx.doi.org/10.2190/16AY-E2GC-DFLD-51X2

Martínez-Hernáez, Àngel. (2008). Antropología Médica. Teorías sobre la cultura, el poder y la enfermedad. Barcelona: Anthropos.

Organización Mundial de la Salud (1992). Décima revisión de la Clasificación Internacional de Enfermedades: Trastornos mentales y del comportamiento: descripciones clínicas y pautas para el diagnóstico. Madrid: Meditor.

Perdiguero, Enrique; Comelles Esteban, Josep $\mathrm{M}^{\mathrm{a}}$ (Eds.) (2000). Medicina y Cultura. Estudios Entre la Antropología y la Medicina. Barcelona: Bellaterra.

Pizza, Giovanni. (2005). “Antonio Gramsci y la antropología médica contemporánea. Hegemonía, "capacidad de actuar" (agency). y transformaciones de la persona". Revista de Antropología Social 14: 15-32.

Radcliffe-Brown, Alfred. (1972 [1952]). Estructura y función en la sociedad primitiva. Barcelona: Península.

Restrepo Uribe, Miguel; Mora, Olga Lucía y Cortés Rodríguez, Ana Cristina. (2007). "Voces del estigma. Percepción de estigma en pacientes y familias con enfermedad mental". Universitas Médica Vol. 43, 3: 207-220.

Robin, Cynthia. (2003). "New directions in classic Maya household archaeology". Journal of Anthropological Research 11: 307-356.

Saraceno, Benedetto. (2008). "Cuatro Dilemas en Salud Mental”, en J. M. Comelles y M. Bernal (Eds.). Salud Mental, Diversidad y Cultura. Madrid: Asociación Española de Neuropsiquiatría Estudios/40.

Sontag, Susan. (1980). La Enfermedad y sus Metáforas. Barcelona: Muchnik.

Stanton, Alfred H. \& Schwartz, Morris R. (1954). The Mental Hospital. A Study of Institutional Participation in Psychiatric Illness and Treatment. New York: Basic Books Inc.

Turner, Victor. (1988 [1969]). El Proceso Ritual: estructura y antiestructura. Madrid: Taurus Van Gennep, Arnold. (1981 [1909]). Les Rites de passage: étude systématique des rites. Paris: Éditions A. et J. Picard.

Zijderveld, Anton. C. (1982). Reality in a looking-glass: Rationality through an Analysis of Traditional Folly. London: Routledge and Kegan Paul. 